\title{
Herpes Zoster Radiculopathy in a Systemic Lupus Erythematosus Patient - A Case Report
}

\author{
Bethasiwi Purbasari1,2 and Shahdevi Nandar Kurniawan ${ }^{1}$ \\ 1. Neurology Department, Faculty of Medicine Brawijaya University, Saiful Anwar General Hospital, Malang, Indonesia; \\ 2. Applied Physiology Department, Faculty of Medicine University of Miyazaki, Miyazaki, Japan.
}

DOI: https://doi.org/10.17925/ENR.2018.13.2.116

B ackground: Motor neuropathy is an extremely rare herpes complication, with a mere prevalence of $0.5-5 \%$. The case of segmental zoster paresis of limbs, resulting from motor radiculopathy, is especially limited, with cervical and thoracic segments being the least frequent. Setting: Neurology outpatient clinic. Case Description: We report a case of a 16-year-old female who presented sudden-onset right upper extremity weakness, a week after her herpes zoster lesions first appeared. As she was diagnosed with systemic lupus erythematosus (SLE) 4 months prior, she routinely consumed steroids and azathioprine. Initial examinations revealed multiple vesicles along right C5-C6 roots dermatome accompanied by upper right extremity weakness (manual muscle test [MMT] 3) corresponding to the myotome of $\mathrm{C} 5$-C6 roots. An electromyography assessment uncovered results relevant to motor root neuritis in $\mathrm{C} 5-\mathrm{C} 6$. Magnetic resonance imaging of the cervical radix with contrast showed no abnormality. Thus, she received acyclovir, gabapentin and physiotherapy. Results: A follow-up visit after 2 weeks revealed an improvement of the weakness along C5-C6 myotome (MMT 4). A month later, all motor functions were restored with hypoesthesia and hypoalgesia sensory sequelae along C5-C6 dermatome. Conclusion: Herpes zoster radiculopathy, though rare, can occur after the onset of characteristic rash. Since cellular-mediated immunity holds crucial roles in varicella zoster virus activation, SLE and immunosuppression therapy is pertinent to this rare motoric complication of herpes. The prognosis is good. Acyclovir, gabapentin and physiotherapy treatments resulted in satisfactory recovery.

\section{Keywords}

Herpes zoster, radiculopathy,

systemic lupus erythematosus

Disclosure: Bethasiwi Purbasari and Shahdevi Nandar Kurniawan have nothing to disclose in relation to this article.

Review Process: Double-blind review.

Compliance with Ethics: All procedures were followed in accordance with the responsible committee on human experimentation and with the Helsinki Declaration of 1975 and subsequent revisions, and informed consent was received from the patient involved in this case study. Authorship: The named authors meet the International Committee of Medical Journal Editors (ICMJE) criteria for authorship of this manuscript, take responsibility for the integrity of the work as a whole, and have given final approval for the version to be published. Open Access: This article is published under the Creative commons Attribution Non-commercial License, which permits any non-commercial use, distribution, adaptation, and reproduction provided the original author and source are given appropriate credit. (c) The Author 2018.

Received: 12 May 2018

Accepted: 3 July 2018

CItation: European Neurological Review. 2018;13(2):116-9

Correspondence: Bethasiwi Purbasari, MD.

Dept of Applied Physiology, Faculty of Medicine,

University of Miyazaki. Miyazaki shi, Kiyotake

Chou Kihara 5200. Miyazaki, Japan, 889-1692.

E: bethasiwi_purbasari@med.miyazaki-u.ac.jp

Funding: No funding was received for

the publication of this article.
Herpes zoster, also known as shingles, is one of the many manifestations of neurologic disorders and occurs with a cumulative life-time incidence of $10-20 \%$ in the general population. ${ }^{1}$ The annual incidence of this disease differs worldwide; in the UK, herpes zoster is found in 0.37 per 1,000 population, with the risk of a second attack being similar to that of a first attack. ${ }^{2}$ The prevalence of herpes zoster in adolescents and children varies between $0.42-1.6$ per 1,000 population, which is increased by the occurrence of HIV infection. ${ }^{3}$ There are several major immune-related factors that increase the risk of herpes zoster, such as old age, malignancies, and immunosuppressant or cytostatic use in patients with autoimmune disorders such as systemic lupus erythematosus (SLE) or HIV infection. ${ }^{4,5}$

Radiculitis and cranial nerve neuritis, caused by herpes zoster, are a result of the reactivation process of varicella zoster virus (VZV) latent infection on sensory ganglion and, in rare cases, motoric ganglion. ${ }^{4.6}$ Previous population studies identified that the incidence of complications resulting in motoric deficit is only $1 \%$ while the incidence of complications affecting central nerve system is only $0.5 \% .^{3}$ The manifestation of motor complications consists of peripheral motor paresis or subclinical motoric involvement. ${ }^{4,7}$ Often, a focal deficit of the motoric nervous system that occurs as a radicular distribution, following the location of affected dermatome, progresses from days to weeks before reaching plateau phase. ${ }^{4,8}$ Several reports in the literature mentioned that the prognosis of zoster infection-induced peripheral paresis is relatively good. ${ }^{8-11}$

In this case report, we present a case of motor radiculopathy caused by VZV infection in a 16-year-old child with history of azathioprine-controlled SLE. The motoric weaknesses were distributed in radix C5-C6, relevant with the appearance of the rash on C5-C6 dermatome. The result of 6 weeks treatment follow-up showed good a response, with improved motoric strength from 1/5 manual muscle test (MMT) score at onset, to 5/5 MMT at the end of follow-up.

\section{Case report}

A 16-year-old female patient presented with weakness of the first digit on the right hand for 1 week before. The symptom came as an abrupt onset and progressively worsened. This condition was accompanied by upper arm weakness. She was also unable to raise her upper right arm, bend her right elbow and to move her right thumb. As a result, this patient experienced difficulties in daily life activities. Additionally, this patient also felt pain in her right shoulder, but still able to bear the pain, represented as scale 4 in Visual Analog Scale Score. One week prior to symptom onset, the 
Figure 1: A 16-year-old female with skin lesion characteristic of herpes zoster, distributed in the right c5-C6 dermatomes

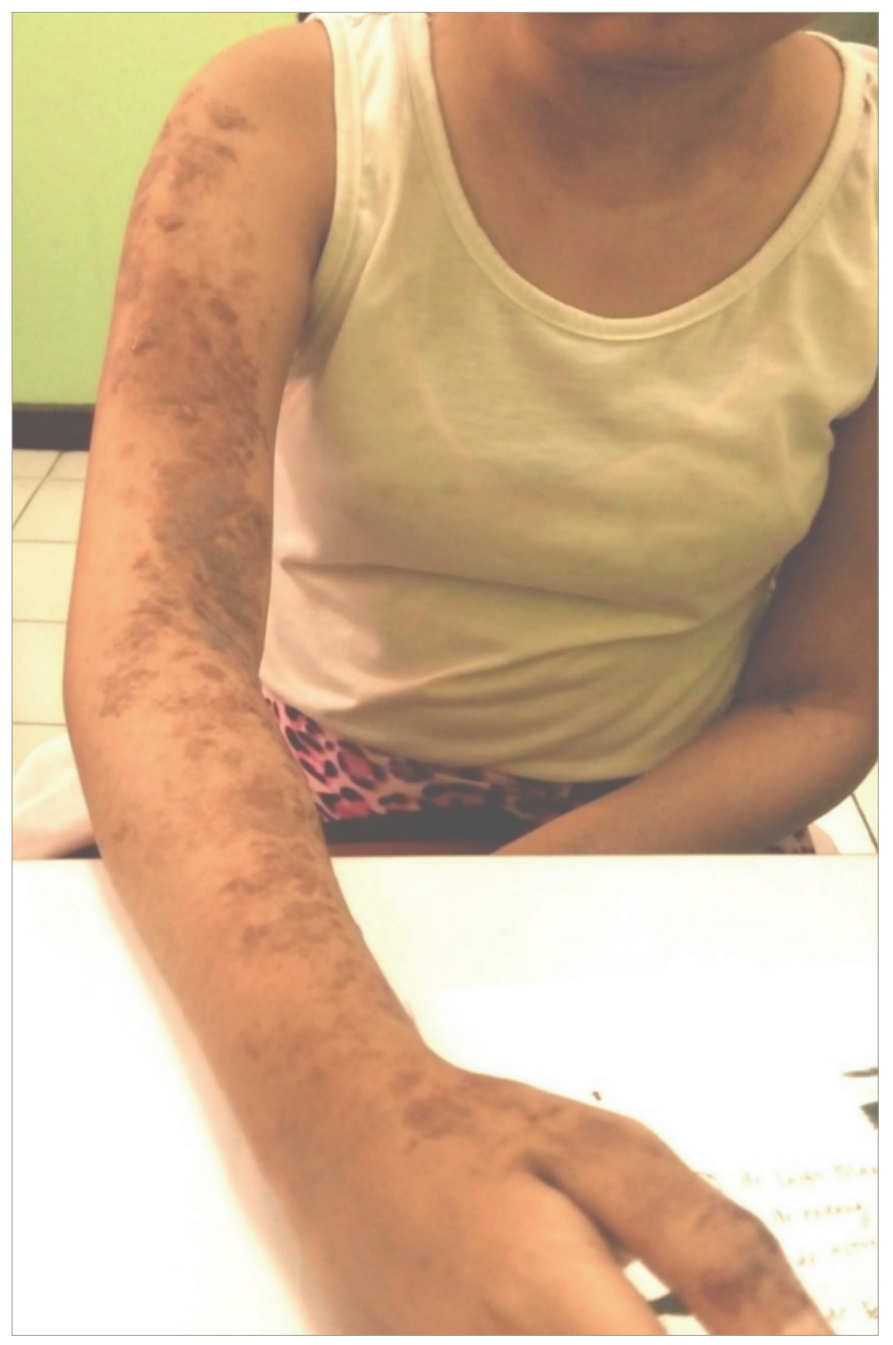

patient suffered a herpes infection with manifestations such as clustered vesicles with red macula base, diffuse border, and irregular structure on her skin (Figure 1). At that time, the dermatologist was able to do a Tzanck test and found the appearance of multinucleated giant cell, and treated the patient with oral acyclovir $5 \times 800 \mathrm{mg}$ dose. The patient had been diagnosed with SLE 4 months previously (positive antinuclear antibody test, positive Anti-dsDNA IgG IgM, positive Coombs test), and has been receiving $3 \times 16 \mathrm{mg}$ methylprednisolone and $2 \times 50 \mathrm{mg}$ azathioprine ever since, as the main treatment of SLE.

The neurologic examination found weaknesses of right shoulder abduction and elbow flexion which was inline with the myotome of right radix $\mathrm{C} 5$ and $\mathrm{C} 6$, with a motoric power score of 3/5 MMT. From Lhermitte and Spurling examinations, we found that the radicular pain spread following the distribution of the right dermatome of the radix C5 and C6, without any sign of hypesthesia. The patient had equal and bilaterally active deep tendon reflexes, and no other signs of cervical myelopathy. Laboratory examination revealed mild hyponatremia (135 mmol/dl) and increased erythrocyte sedimentation rate at $45 \mathrm{~mm} /$ hour. Cervical magnetic resonance imaging with contrast revealed no peculiarities other than multiple cervical lymphadenopathies (Figure 2).

Bilateral nerve conduction study and electromyography (EMG) were performed for the median and ulnar nerves. The amplitude of motor
Figure 2: Axial T2-weighted resonance image at C5-C6 vertebral level $(A)$ without contrast $(B)$ with contrast, was in normal limit

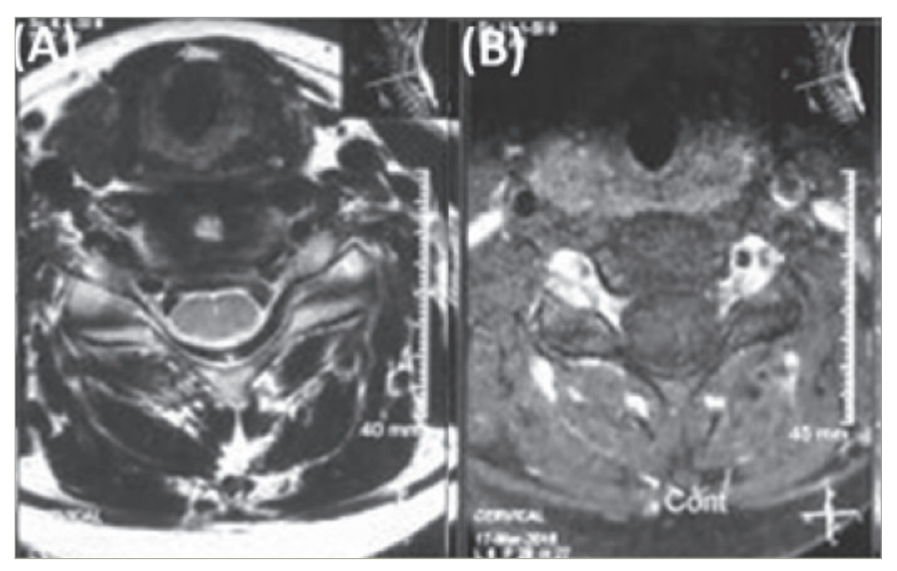

responses was decreased for the right median and ulnar nerves. Sensory nerve conduction velocity was in normal limit. Needle EMG examination showed denervation potentials (positive sharp waves) in the right biceps, deltoid, and brachioradialis. These findings were consistent with a right C5-C6 radiculopathy. The patient was informed that cerebrospinal fluid (CSF) study was recommended, which she refused.

The patient received acyclovir for 2 weeks and was administered gabapentin and an analgesic for the neuropathic pain over the next 4 weeks. She also underwent a physical therapy and rehabilitation programme, which focused on strengthening of the right shoulder. After 4 weeks, her examinations revealed increased shoulder range of motion and completely improved muscle strength (MMT 5/5). The skin lesions were still present but showed marked regression. All motor functions were restored with hypoaesthesia and hypoalgesia sensory sequelae along the C5-C6 dermatome. Evaluative EMG revealed median nerve neuritis.

\section{Discussion}

Herpes zoster virus is a neurotropic virus, derived from herpes virus family, and is caused by a reactivation of dormant viruses which then spread through the sensory nerves. ${ }^{12-13}$ The annual incidences of herpes zoster are clustered based on the population age and immunity status; with 0.4-1.6 incidences per 1,000 population $<20$ years old and $4.5-11$ incidences per 1,000 population aged $\geq 80$ years. ${ }^{13,14}$ This disease is commonly observed in the elderly, in immunocompromised hosts, and in patients with SLE. ${ }^{5,15-18}$ Cell-mediated immunity plays an important role in preventing the reactivation of the virus. ${ }^{19}$ T-cell mediated immunity, which is detected within 1-2 weeks after appearance of rash, consists of both CD4 and CD8 effector and memory cells, and is essential for recovery from varicella. 19,20 Hence, patients with SLE may be at increased risk for zoster infection by virtue of both the impairment in cell-mediated immunity, which characterises the disease, and by treatment with high dose corticosteroid or immunosuppressive agents. On the other hand, several studies have reported an increased incidence of herpes zoster in patients with SLE. ${ }^{13,17,18}$ In this case report, one of the risk factors inducing the reactivation of zoster virus in patient's body is the presence of SLE, and corticosteroid and azathioprine usage as the main treatment for SLE.

Herpes zoster virus has multi-variant neurologic manifestations, such as post-herpetic neuralgia, myelitis, encephalitis, arteritis cranialis, and in rare cases, polyradiculitis. ${ }^{17,75}$ The incidence of involvement of motor fibres secondary to herpes zoster is reported to be between $0.9-1 \% .{ }^{89,21,22}$ The hallmark feature of radiculitis is isolated muscle weakness due to 
peripheral motor neuropathy. The diagnostic approach is easier with the presence of rash manifestation. In more than $90 \%$ of patients, radicular symptoms, which occur in association with affected dermatome, are accompanied by sensory deficit, pain and worsened by muscle weakness. ${ }^{11}$ In several cases, there can also be a dissociation between dermatome and affected myotome. ${ }^{6,8-10}$ In this case report we found that the presence of motoric weakness was associated with the myotome of right radix $\mathrm{C5}$-C6 with motoric power at 3/5 MMT. The weakness occurred in accordance to the rash manifestation seen on right dermatome C5-C6. The resulting radicular pain from Lhermitte and Spurling test supported the existence of radiculopathy process.

Herpes zoster infection is a result of latent varicella virus reactivation. After the reactivation, the virus will spread inside sensory ganglion and is centrifugally distributed through peripheral nerves, which then manifest as a vesicular rash dermatome on patient's skin. Although skin type-herpes zoster is the main manifestation of affected afferent sensory nerves, some motoric involvement can also be found. An early report by Broadbent in 1866 showed the correlation between motoric weakness and herpes zoster, in which he reported that 1-5\% patients with herpes zoster had motoric paresis complications on affected radix-innervated muscles. ${ }^{23}$ Motor involvement in herpes zoster is due to the spread of infection from dorsal root ganglia to the same segment of spinal cord mainly in posterior horn and occasionally to anterior horn cells with consequent lower motor neuron paralysis. Lower motor neuron paralysis may also occur from damage to the anterior nerve root where it joins the dorsal root ganglia. ${ }^{24}$ Further post mortem studies found evidence of dorsal horn atrophy and cell, axon and myelin loss with fibrosis in the sensory ganglion. ${ }^{25}$ The exact mechanism of this unusual spread of herpes zoster has not been established, but pathological and neuroradiological studies indicate that the virus spreads proximally as well as distally, causing local neuritis in the spinal nerve, anterior horn cells, and the anterior root. ${ }^{26}$ The basic pathological neural reaction to herpes zoster is axonal degeneration with a degree of secondary segmental demyelination. ${ }^{12,27}$ Histopathologic manifestations of herpes zoster are: ganglionitis, the involvement of radix and anterior and posterior horn, leptomeningitis, and peripheral neuritis. ${ }^{12,25}$ The prevalence of proximal and/or distal myotome involvement in upper and lower extremities is relatively similar, although some studies have reported that the tendency for upper extremities (predilection on myotome C5-C6) are twice as common as lower extremities. ${ }^{8.12}$

Motoric paresis due to herpes zoster usually occurs in first few weeks after onset of skin rash, ${ }^{20}$ but several studies have reported that this symptom can be found after 2-3 weeks after the onset of vesicular rash. ${ }^{9,21}$ Moreover, a 3.5-month interval between rash onset and motoric paresis has also found in another case report. ${ }^{28}$ The prognosis of motoric paresis due to herpes zoster is relatively positive. More than half of patients show complete recovery after 6-12 months. ${ }^{11}$ In the case reports mentioned above, motoric weakness occurred 1 week after the onset of vesicular rash and recovered 6 weeks after onset.

Even though it lacks the specificity to diagnose the cause of nerve lesion, EMG examination can help to identify the location of nerve lesion and monitor the degree of nerve damage during the follow-up session. In the previous study by Haanpää, of 40 immunocompetent patients with herpes zoster, $53 \%$ of patients had abnormalities in EMG, 33\% patients had subclinical abnormalities, and $20 \%$ patients showed motoric paresis abnormalities. ${ }^{29}$ The EMG result was consistent with the myotome of the same rash dermatome in $23 \%$ patients, and involved a broader area in other 30\% patients. Even though all rashes were unilaterally expressed, the EMG abnormalities were found in bilateral paraspinal muscles in six patients. ${ }^{29}$ Abnormal EMG findings also showed correlation with polyneuropathy. ${ }^{30}$ These findings highlight the importance of electrophysiology evaluation to diagnose the presence of any motoric involvement in herpes infection. Typical EMG findings in radiculopathy are: reduced recruitment, fibrillations, and positive sharp waves or polyphasic motor unit potentials in muscles supplied by affected root. ${ }^{29}$ Although nerve conduction velocity examination usually shows normal results, the result of compound muscle action potential (CMAP) test can show a decreased amplitude. ${ }^{26}$ The result of EMG examination of our patient showed decreased amplitude of CMAP in ulnar and median nerves, both proximal and distal. Additionally, the examination using needle EMG revealed positive sharp waves, which represent denervation potentials in the right bicep, deltoid and brachioradialis. These findings were consistent with a right $\mathrm{C} 5-\mathrm{C} 6$ radiculopathy. On the other hand, the result of EMG examination after 6 weeks of therapy showed decreased amplitude of CMAP in only right median nerve, which proves reduced damage of the nerve radix, with sequelae of median nerve neuritis.

The International Herpes Management Forum recommend that where neurologic complications associated with VZV are suspected, CSF should be analysed to evaluate the presence of VZV antibodies or VZV DNA. ${ }^{31}$ In a study with 56 immunocompetent patients with herpes zoster and without clinical symptom of neurologic complication, CSF was obtained on days 1-18. In $35 \%$ of the patients, there was evidence of VZV in the CSF. Leucocytosis was found in $46 \%$ patients. ${ }^{32}$ CSF analysis could not be conducted in the present case study, because our patient refused CSF examination as it is an invasive procedure.

The mainstay of treatment of motor paresis of brachial plexus neuritis due to shingles is antivirals, pain relief, physiotherapy and occupational therapy. The commonly used antiviral is acyclovir. ${ }^{33}$ Steroids are also suggested to be beneficial in suppressing severe infections in skin lesions, and the initiation of IV acyclovir and IV steroids is recommended as soon as zoster paresis is suspected. ${ }^{34}$ We administered acyclovir for the medical therapy of zoster virus and also gave gabapentin and analgesic treatment to our patient as a medical therapy for the neuropathic pain. After 4 weeks post onset, the motoric strength started to return to normal, the rash almost completely disappeared, and the sequelae were minimal, with only hypesthesia and hypoalgesia in right dermatome C5-C6. The patient was put on a physical therapy and rehabilitation programme to prevent muscle atrophy and contracture as well as to strengthen the muscle. We believe that physical therapy and rehabilitation were significantly involved in complete motor improvement and the lack of a joint contracture.

\section{Conclusion}

Here we describe a case of right C5-C6 radiculopathy secondary to herpes zoster infection, and this diagnosis should be considered in determining the differential diagnosis of acute paresis developing in the upper extremity. A good understanding of the neurologic complications secondary to herpes zoster infection would provide the opportunity for early diagnosis and treatment to prevent severe morbidity. \ 
1. Schmader KE, Dworkin RH. The Epidemiology and Natural History of Herpes Zoster and Postherpetic Neuralgia In: Watson C Gershon A, Oxman M. (eds) Herpes Z0ster: Postherpetic Neuralgia and Other Complications. Adis, 2017;39-64.

2. Brisson M. Edmunds WJ. Epidemiology of varicella-zoster virus in England and Wales. I Med Virol. 2003;70:S9-14.

3. Haanpää M. Polyneuropathies and pain: acute herpes zoster pain. In: Cervero F, Jensen T. Handbook of Clinical Neurology, vol 81 (3rd series). Amsterdam, Elsevier, 2006;653-7.

4. Nations SP, Trivedi JR, Wolfe GI. Infectious and Granulomatous Neuropathies. In: Bromberg MB, Smith AG. Handbook of Peripheral Neuropathy. Boca Raton, Taylor \& Francis Group, 2005;307-9.

5. Jung BF, Johnson RW, Griffin DR, Dworkin RH. Risk factors for postherpetic neuralgia in patients with herpes zoster. Neurology. 2004;62:1545551.

6. Saleh FG, Pourmand R. Radiculopathy. In: Bromberg MB, Smith AG. Handbook of Peripheral Neuropathy. Boca Raton, Taylor \& Francis Group, 2005;439-49.

7. Haanpää M. Neurological Complications of Herpes Zoster In: Watson C, Gershon A, Oxman M. (eds) Herpes Zoster: Postherpetic Neuralgia and Other Complications. Adis, 2017;89-96.

8. Akiyama N. Herpes zoster infection complicated by moto paralysis. J Dermatol. 2000;27:252-7.

9. Yaszay B, Jablecki CK, Safran MR. Zoster paresis of the shoulde Case report and review of the literature. Clin Orthop Relat Res. 2000;377:112-8

10. Jeevarethinam A, Ihuoma A, Ahmad N. Herpes zoster brachia plexopathy with predominant radial nerve palsy. Clin Med. 2009;9:500-1

11. Unlu E, Ulas UH, Odabasi Z, et al. Herpes zoster radiculopathy: report of two cases. I Neurol SC. 2005:22:319-24.

12. Head H, Campbell AW. The pathology of herpes zoster and its bearing on sensory localisation. Brain. 1900;23:353-523.

13. Whitley JR. Infections due to DNA Viruses: Varicella-Zoster Virus Infections. In: Fauci AS, Braunwald E, Kasper DL, et al. Harrison's Principle of Internal Medicine, 17th edition. New York, Mc Graw Hill, 2008:1102-5.

14. Scott FT, Leedham-Green ME, Barrett-Muir WY, et al. A study of shingles and the development of postherpetic neuralgia in Eas don. J Med Virol. 2003:70(Suppl. 1):S24-30.

5. Martin del Pozo M, Benito-Leon J, Rodriguez J, et al. Uncommon neurologic complications related to varicella-zoster virus. Neurologica. 1998;13:94-7.

16. Kang TY, Lee HS, Kim TH, et al. Clinical and genetic risk actors of herpes zoster in patients with systemic lupus erythematosus. Rheumatol Int. 2005:25:97-102.

17. Manzi S, Kuller LH, Kutzer J, et al. Herpes zoster in systemic lupus erythematosus. J Rheumatol. 1995;22:1254-8.

18. Sayeeda A, Al Arfaj H, Khalii N, Al Arfaj AS. Herpes zoster infections in SLE in a university hospital in Saudi Arabia risk factors and outcomes Autoimmune Dis. 2010:2010:174891.

19. Arvin AM Varicella-zoster virus Clin Microbiol Rev. 1996;9:361-81.

20. Sterling JC, Kurtz JB. Varicella (Chickenpox) and zoster (shingles). In: Champion RH, Burton JL, Burns DA, Breathnach SM (eds). Rook, Wilkinson, Ebling Textbook of Dermatology. 6th edition. London: Blackwell Scientific Publications. 1998;1015-22.

21. Grauvogel J, Vougioukas VI. Herpes radiculitis following surgery for symptomatic cervical foraminal stenosis. Can I Neurol SCi. 2008:42:398-425

22. Lyngberg KK, Sensson BH. Herpes zoster paresis. A review of the literature and case reports [Article in Danish]. Ugeski Laeger. 1990:152:1214-7.

23. Broadbent WH. Case of herpetic eruption in the course of branches of the brachial plexus followed by partial paralysis in corresponding motor nerves. Br Med J. 1866;2:460.
24. Bradley GB. Myelopathies affecting anterior horn cells. In: Dyck PJ, Thomas PK, Lambert HE, Bunge R (eds). Peripheral Neuropathy 6 th edition. Philadelphia, WB Saunders, 2012;2006-9.

25. Watson CPN, Deck HJ, Morshead C, et al. Post-herpetic neuralgia: further post-mortem studies of cases with and without pain. Pain. 1991;44:105-17.

26. Santiago-Pérez $S$, Nevado-Estévez R, Pérez-Conde MC. Herpes zoster-induced abdominal wall paresis: neurophysiological examination in this unusual complication. J Neurol Sci. 2012;312:177-9

27. Hanakawa T, Hashimoto S, Kawamura J, et.al. Magnetic resonance imaging in a patient with segmental zoster paresis. Neurology. 1997;49:631-2.

28. Gupta SK, Helal BH, Kiely P. The prognosis in zoster paralysis J Bone Joint Surg Br. 1969:51:593-603

29. Haanpää M, Häkkinen V, Nurmikko T. Motor involvement in acute herpes zoster. Muscle Nerve. 1997:20:1433-8.

30. Kinesya B, Husna M, Kurniawan SN, Ridwan M. Amplitudo sensory neuron action potential using as installation of polyneuropathy diagnosis. MNJ. 2018;4:7-11.

31. Gilden D. Varicella zoster virus and central nervous system syndromes. Herpes. 2004:11(Suppl 2): 89-94.

32. Haanpää M, Dastidar P, Weinberg A., et al. . CSF and MP findings in patients with acute herpes zoster. Neurology. 1998; $51: 1405-1411$

33. Whitley RJ, Weiss H, Gnann JW Jr., et al. Aciclovir with and without prednisone for the treatment of herpes zoster a randomized, placebo-controlled trial. Ann Intern Med. 1996;125:376-83

34. Mondelli M, Romano C, Passero S, et al. Effects of acyclovir on sensory axonal neuropathy segmental motor paresis and posttherapeutic neuralgia in herpes zoster patients. Eur Neurol. 1996;36:288-92. 